\title{
Synthesis and Characterization of Divalent Nickel, Copper and Cadmium Complexes of N-(2-2-[1-(3-aminophenyl) ethylidene] hydrazino-2-oxoethyl) Benzamide
}

\author{
TH. PROMILA DEVI ${ }^{1}$ and R. K. LONIBALA* \\ Department of Chemistry, Manipur University, Canchipur - 795003, Manipur, India \\ ${ }^{1}$ Department of Chemistry, Liberal College, Luwangshangbam, Imphal, Manipur \\ ${ }^{*}$ Corresponding author E-mail: lonirk@yahoo.co.uk \\ http://dx.doi.org/10.13005/ojc/300468
}

(Received: September 16, 2014; Accepted: November 03, 2014)

\begin{abstract}
Complexes of $\mathrm{Ni}(\mathrm{II})$ (1), $\mathrm{Cu}(\mathrm{II})$ (2) and $\mathrm{Cd}(\mathrm{II})$ (3) with a novel Schiff base N-(2-2-[1-(3aminophenyl) ethylidene] hydrazino-2-oxoethyl) benzamide (LH) have been prepared and characterized by elemental analysis, TG-DTA, magnetic, electronic, molar conductivity measurements, IR, SEM, NMR, ESR and mass studies. It is observed that all the complexes having 1:1 metal-ligand stoichiometry are tetracoordinated. The result shows that $\mathrm{LH}$ binds to $\mathrm{Cu}$ and $\mathrm{Cd}$ ions through the hydrazidic carbonyl oxygen, azomethine nitrogen and amine nitrogen as a tridentate ligand while with $\mathrm{Ni}$ ion, it coordinates as a bidentate species through the hydrazidic carbonyl oxygen and azomethine nitrogen. The ligand exhibits keto-enol tautomerism in 2 in which it acts as a uninegative ligand. Complexes 1 and 3 behave as 1:1 electrolytes in DMF solution while complex 2, as a nonelectrolyte. Complex 2 is diamagnetic and ESR inactive which suggest that copper ion is present in its cuprous form. SEM images are used to observe external morphology of the compounds.
\end{abstract}

Key words : Schiff base; Tautomerism; Spectral studies; SEM images.

\section{INTRODUCTION}

Study of the coordination of transition metal ions with different types of ligands has been amplified by the recent developments in the field of bioinorganic chemistry and medicines ${ }^{1}$. Metal Complexes of N,O-donor ligands in particular, have played a prominent role in this area because many of these complexes may serve as model for biologically important species such as metalloenzymes ${ }^{2}$ and also have a variety of applications in biological, clinical, analytical and industrial fields in addition to their important roles in catalysis and organic synthesis ${ }^{3-8}$. It is believed that ligands containing different donor atoms like $\mathrm{O}-\mathrm{N}$ type form more stable complexes than those containing either $\mathrm{O}-\mathrm{O}$ or $\mathrm{N}-\mathrm{N}$ types ${ }^{9}$. Amino acids and their derivatives are extensively studied as typical N,O-donor ligands. In the N-protected amino acids, the introduction of a substituent such as 
acetyl, benzoyl or benzylo carbonyl group directly on the amino group, could reduce the ligand field of the in-plane donor thus diminishing the affinity of the amino group for the metal ion and permitting a variety of co-ordinating type. These aroyl hydrazones, moreover, not only possess many potential donor sites but there is also possibility of keto-enol toutomerism which may lead to varied bonding and stereochemical behavior in the complexes in which they act as neutral or mononegative or even as dianionic ligands depending on the aroyl substituents and the reaction conditions ${ }^{10,11}$. Their chemistry has also been intensely investigated owing to their cooperative capability ${ }^{12,13}$, pharmacological activity ${ }^{14-18}$ and use in analytical chemistry as metal extracting agents ${ }^{19}$.

Considering the above facts and in continuation to our work ${ }^{20-28}$, we have synthesized a novel Schiff base, N-(2-2-[1-(3-aminophenyl) ethylidene] hydrazino-2-oxoethyl) benzamide (LH, Fig. 1) and studied its ligational behavior towards $\mathrm{Ni}(\mathrm{II}), \mathrm{Cu}(\mathrm{II})$ and $\mathrm{Cd}(\mathrm{II})$ ions.

\section{MATERIALSAND METHODS}

$\mathrm{N}$-benzoyl glycine, hydrazine hydrate, 3aminoacetophenone and metal salts, $\mathrm{MCl}_{2} \cdot \mathrm{nH}_{2} \mathrm{O}(\mathrm{M}$ $=\mathrm{Cu}, \mathrm{Ni}$ and $\mathrm{Cd}$ ) were purchased from E-Merck and used as such. All the other chemicals and solvents used in the study were of AnalaR grade. The ligand N-(2-2-[1-(3-aminophenyl) ethylidene] hydrazino-2-oxoethyl)benzamide, LH was prepared by the condensation of $\mathrm{N}$-benzoyl glycine with 3aminoacetophenone as reported ${ }^{24}$.

The metal contents and chlorine were estimated gravimetrically using standard literature procedures $^{29}$. Hydrazine was determined volumetrically ${ }^{29}$ by $\mathrm{KIO}_{3}$ method after subjecting the ligand/complexes to acid hydrolysis with $6 \mathrm{~N} \mathrm{HCl}$ for about $4 \mathrm{~h}$.

Molar conductance of the $10^{-3} \mathrm{M}$ solution of complexes in $10^{-3} \mathrm{M}$ DMSO were measured using a Systronic Conductivitymeter 306 while $\mathrm{C}, \mathrm{H}$ and $\mathrm{N}$ were microanalyzed on a Perkin-Elmer model 240C Analyzer. Magnetic susceptibility measurements of the complexes were carried out on a Magnetic Susceptibility Balance, Sherwood Scientific Cambridge, UK. Electronic spectra of the complexes were taken on a Shimadzu 2450 UVVis Spectrophotometer. IR spectra of the ligand and the complexes were obtained using a Shimadzu Fourier Transform Infrared Spectrophotometer $8400 \mathrm{~S}$ in $\mathrm{KBr}$ medium. ${ }^{1} \mathrm{H}$ NMR spectra were recorded in DMSO-d 6 on a Jeol AL 300 FT NMR Spectrometer. Mass spectra were obtained on a Jeol Sx102/Da-6000 Mass Spectrometer. Thermoanalytical (TG/DTA) measurements were carried out with Perkin Elmer Simultaneous Thermal analyzer STA 6000. SEM and EDAX images of the complexes were obtained using a Quanta 250 scanning electron microscope (SEM) fitted with an Ametek Energy Dispersive X-ray Analysis (EDAX) system.

\section{Preparation of $\mathrm{Ni}$ (1), $\mathrm{Cu}(2)$ and $\mathrm{Cd}(3)$ complexes}

Ethanolic solution of ligand $(1 \mathrm{mmol}, 1 \mathrm{~g}$ in $20 \mathrm{~mL}$ ethanol) was refluxed with ethanolic solutions of the metal chloride $\left(\mathrm{MCl}_{2} \cdot \mathrm{nH}_{2} \mathrm{O}\right)(2 \mathrm{mmol}, 1.5 \mathrm{~g}$ in $10 \mathrm{~mL}$ ethanol) for $4 \mathrm{~h}$ and cooled. Complex 2 was obtained on keeping the reaction mixture overnight. However, in case of complexes $\mathbf{1}$ and $\mathbf{3}$, the reaction mixtures were refluxed for $\sim 20 \mathrm{~h}$ and the solid complexes could be isolated only after vigorous stirring the concentrated reaction solution with $\sim 20$ $\mathrm{mL}$ of acetonitrile and THF. The precipitate obtained were filtered, washed with ethanol/solution mixture of acetonitrile and THF and dried in desicator (yield: $60-70 \%)$.

\section{RESULTS AND DISCUSSION}

The ligand, $\mathrm{LH}$ reacts with $\mathrm{Ni}^{+2}, \mathrm{Cu}^{+2}$ and $\mathrm{Cd}^{+2}$ ions in ethanolic medium to form complexes having 1:1 metal - ligand stoichiometry. All the complexes are stable. They are insoluble in water and common organic solvents but soluble in coordinating solvents such as DMF and DMSO. The complexes are characterized by $\mathrm{C}, \mathrm{H}, \mathrm{N}, \mathrm{Cl}$ and hydrazine analysis. The observed and calculated data are in good agreement and support one ligand to a metal ion. The composition of the isolated complexes is independent of the relative ratio of the starting materials taken for their synthesis. The analytical data along with the molar conductance values of the complexes are summarized in Table 1. The conductance value (Table 1) in 0.001 M DMF 
Table 1: Physical and analytical data of the ligand and the complexes

\begin{tabular}{|c|c|c|c|c|c|c|c|c|c|}
\hline \multirow{2}{*}{$\begin{array}{l}\text { Compound/Complex } \\
\text { Molecular wt }\end{array}$} & \multirow[t]{2}{*}{ Color } & \multirow{2}{*}{$\begin{array}{l}\text { m.pt } \\
\left({ }^{\circ} \mathrm{C}\right)\end{array}$} & \multicolumn{6}{|c|}{ Found (Calcd) (\%) } & \multirow{2}{*}{$\begin{array}{l}\text { Molar } \\
\text { Cond } \\
\text { ucta } \\
\text { nce }\end{array}$} \\
\hline & & & $M$ & $\mathrm{Cl}$ & C & $\mathbf{H}$ & $\mathbf{N}$ & $\mathrm{N}_{2} \mathrm{H}_{4}$ & \\
\hline LH & White & 215 & - & - & - & $\begin{array}{c}5.89 \\
(5.80)\end{array}$ & $\begin{array}{c}17.87 \\
(18.06)\end{array}$ & $\begin{array}{r}10.40 \\
(10.32\end{array}$ & - \\
\hline $\begin{array}{l}{\left[\mathrm{Ni}(\mathrm{LH})\left(\mathrm{H}_{2} \mathrm{O}\right) \mathrm{Cl}\right] \mathrm{Cl}} \\
\text { (1) } 458.69\end{array}$ & Green & 220 & $\begin{array}{c}12.90 \\
(12.80)\end{array}$ & $\begin{array}{c}14.95 \\
(15.48)\end{array}$ & $\begin{array}{c}44.01 \\
(44.47)\end{array}$ & $\begin{array}{c}4.22 \\
(4.36)\end{array}$ & $\begin{array}{l}12.18 \\
(12.21)\end{array}$ & $\begin{array}{c}6.89 \\
(6.98)\end{array}$ & 65 \\
\hline $\begin{array}{l}{\left[\mathrm{Cu}(\mathrm{L})\left(\mathrm{H}_{2} \mathrm{O}\right)\right] \mathrm{H}_{2} \mathrm{O}(2)} \\
391.54\end{array}$ & $\begin{array}{l}\text { Light } \\
\text { Grey }\end{array}$ & $>250$ & $\begin{array}{l}15.80 \\
(16.23)\end{array}$ & - & $\begin{array}{l}51.87 \\
(52.10)\end{array}$ & $\begin{array}{l}4.60 \\
(4.86)\end{array}$ & $\begin{array}{l}13.78 \\
(14.32)\end{array}$ & & - \\
\hline $\begin{array}{l}{[\mathrm{Cd}(\mathrm{LH}) \mathrm{Cl}] \mathrm{Cl}(3)} \\
494.5\end{array}$ & Cream & 250 & $\begin{array}{l}22.71 \\
(22.65)\end{array}$ & $\begin{array}{c}14.25 \\
(14.36)\end{array}$ & $\begin{array}{c}41.20 \\
(41.25)\end{array}$ & $\begin{array}{l}3.61 \\
(3.64)\end{array}$ & $\begin{array}{l}11.26 \\
(11.32)\end{array}$ & $\begin{array}{l}6.43 \\
(6.47)\end{array}$ & 75 \\
\hline
\end{tabular}

Molar conductance ${ }^{*}$ in $\Omega^{-1} \mathrm{~cm}^{2} \mathrm{~mol}^{-1}$ in DMF

Table 2: IR spectral bands $\left(\mathrm{cm}^{-1}\right)^{*}$ of $\mathrm{LH}$ and the complexes with their assignments

\begin{tabular}{|c|c|c|c|c|c|c|c|c|}
\hline \multirow{2}{*}{$\begin{array}{l}\text { Ligand/M: } \\
\text { Complex }\end{array}$} & \multicolumn{2}{|c|}{ Hydrazidic moiety } & \multirow[t]{2}{*}{$v(\mathrm{CN})$} & \multirow[t]{2}{*}{$v(N N)$} & \multirow{2}{*}{$\begin{array}{l}\mathrm{NH}_{2} \\
\text { bands }\end{array}$} & \multirow[t]{2}{*}{$v(\mathrm{MO})$} & \multirow[t]{2}{*}{$v(\mathrm{MN})$} & \multirow[t]{2}{*}{$v(\mathrm{MCl})$} \\
\hline & Amide I & Amide II & & & & & & \\
\hline LH & 1688 & 1577 & 1597 & 995 & 1026,597 & - & - & - \\
\hline $\mathrm{Ni}: 1$ & 1658 & 1537 & 1546 & 1041 & - & 540 & 401 & 362 \\
\hline Cu:2 & 1681 & - & 1579 & 1024 & 989,588 & 513 & 412 & - \\
\hline Cd:3 & 1672 & 1546 & 1589 & 1016 & 989,588 & 543 & 486 & 410 \\
\hline
\end{tabular}

*Bands are recorded as $\mathrm{KBr}$ pellets

Table 3: ${ }^{1} \mathrm{H}$ NMR spectral data* of LH and complex 3

\begin{tabular}{lll}
\hline Protons(s), $\boldsymbol{\delta}$ & LH & complex 3 \\
\hline$-\mathrm{N}-\mathrm{N} \underline{\mathrm{H} C O}$ & $10.92^{\mathrm{s}}$ & $10.63^{\mathrm{s}}$ \\
$\mathrm{C}_{6} \mathrm{H}_{5} \mathrm{CON} \underline{\mathrm{H}}-$ & $8.98^{\mathrm{d}}$ & $8.83^{\mathrm{t}}$ \\
$-\mathrm{NC}-\mathrm{C} \underline{H}_{3}$ & $2.50^{\mathrm{d}}$ & $2.19^{\mathrm{s}}$ \\
$-\mathrm{C}_{2}-$ & $4.77^{\mathrm{s}}$ & $4.44^{\mathrm{s}}$ \\
$-\mathrm{NH}_{2}$ & $5.44^{\mathrm{s}}$ & $5.14^{\mathrm{s}}$ \\
Phenyl ring & $(6.93-8.22)$ & $(6.58-7.91)$ \\
\hline
\end{tabular}

*NMR spectra are recorded in $\mathrm{dmso} \mathrm{d}_{6},{ }^{\mathrm{s}}$ singlet; ${ }^{\mathrm{d}}$ doublet; ${ }^{t}$ triplet

solution at $30^{\circ} \mathrm{C}$ shows nonelectrolytic behavior of complex 2 and 1:1 electrolytic behavior of complexes 1 and $\mathbf{3}^{30}$.

\section{Thermal Analysis}

TG and DT analysis of 1 and 3 were carried out in the temperature range $40-940^{\circ} \mathrm{C}$.
TG/DTA curves of $\mathbf{2}$ show that the complex decomposes in two steps. The weight loss observed in the temperature ranges $120-250^{\circ} \mathrm{C}$ and 342 $580^{\circ} \mathrm{C}$, respectively, correspond to decomposition of one coordinated water and one ligand molecule. Thermogravimetry data reveals that $\mathbf{3}$ is thermally stable up to $245^{\circ} \mathrm{C}$. The first decomposition of the complex occurs at 250 to $297^{\circ} \mathrm{C}$ and the second step starts at $503^{\circ} \mathrm{C}$ and completes at $744^{\circ} \mathrm{C}$ indicating the absence of any lattice/coordinated water molecule. Total weight loss of this complex corresponds to the decomposition of two $\mathrm{Cl}^{-}$ions and one ligand molecule. The residue left after complete decomposition of both the complexes are the stable metal oxides.

Magnetic Moment and Electronic Spectral studies The observed $\mu_{\text {eff }}$ value of 1 is 3.65 B.M. which falls in the range reported for tetrahedral $\mathrm{Ni}(\mathrm{II})$ complex ${ }^{31}$. A strong multiple band at $638 \mathrm{~nm}$ observed in the electronic spectrum of the complex is assignable to the transition ${ }^{3} \mathrm{~T}_{1}(\mathrm{~F}) \rightarrow{ }^{3} \mathrm{~T}_{1}(\mathrm{P})$ for a 


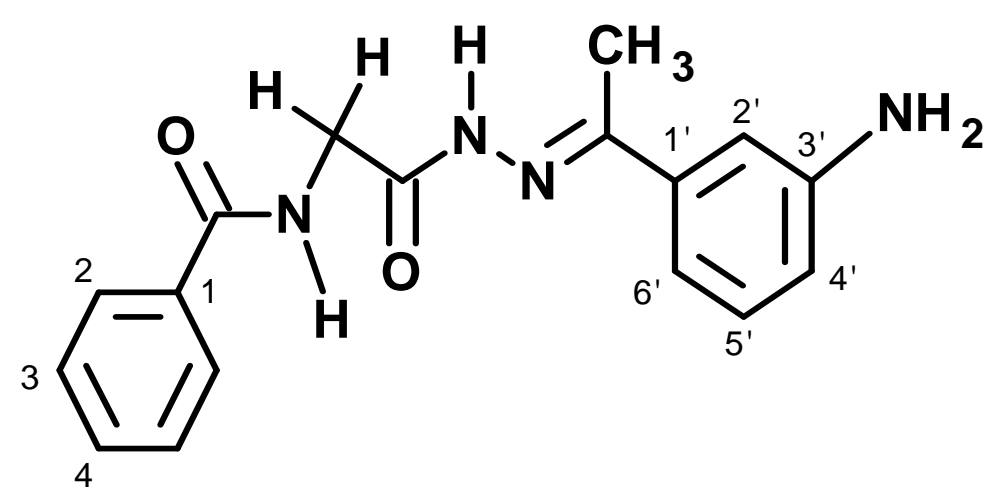

Fig. 1: Structure of LH
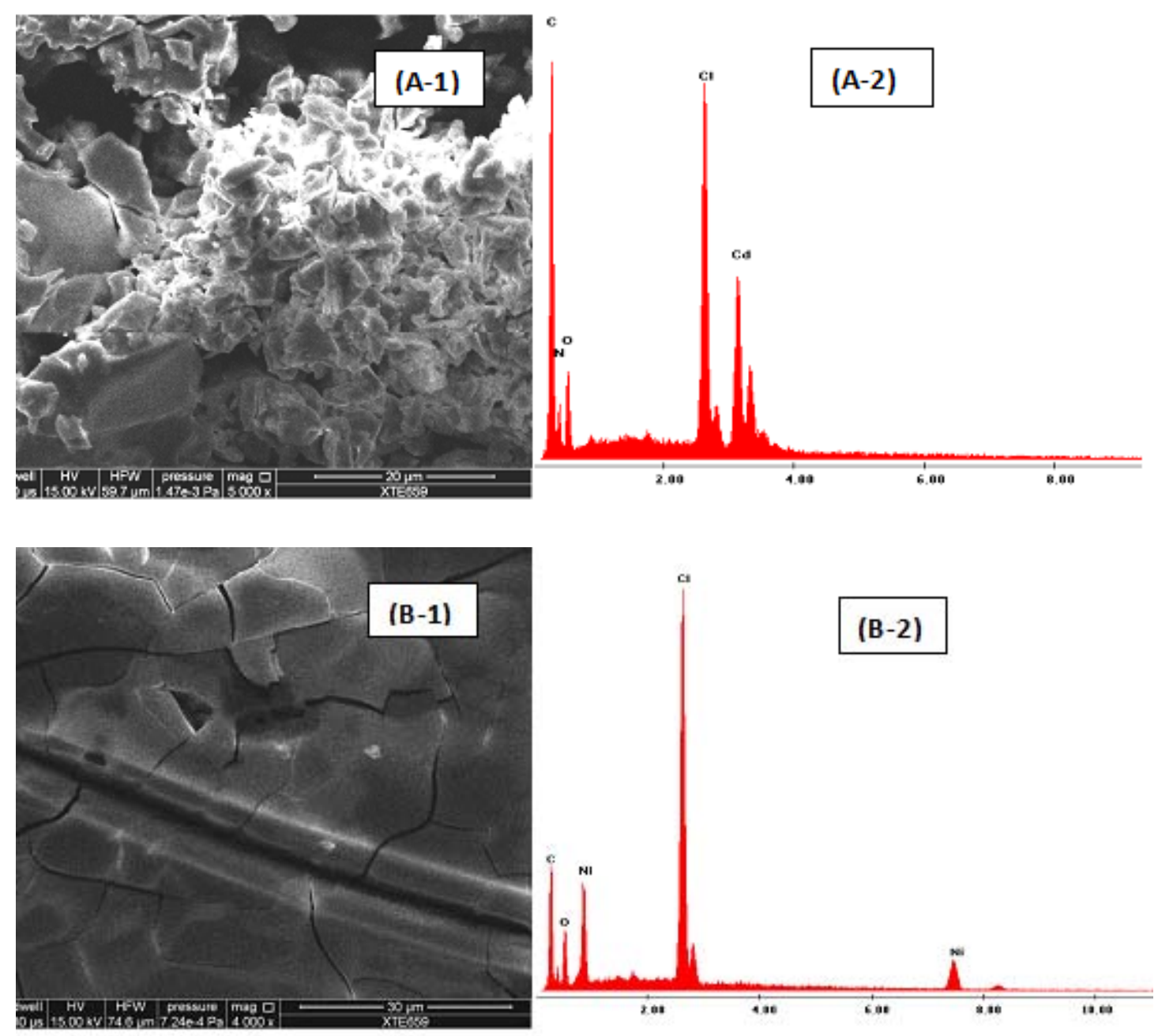

Fig. 2: (A-1): SEM image \& (A-2) EDAX image of Cd(II) complex, (B-1) SEM image \& (B-2) EDAX image of Ni(II) complex 

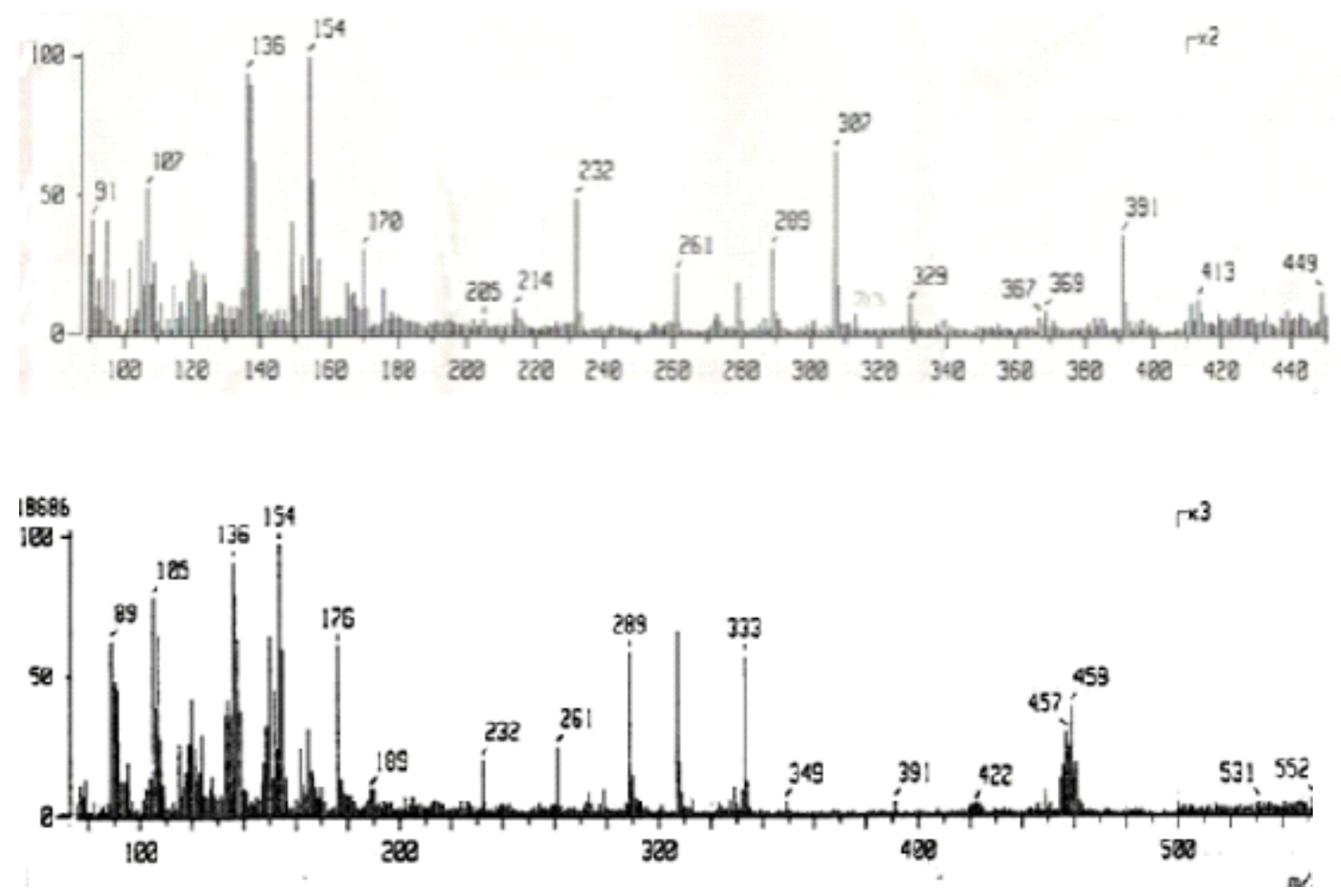

Fig. 3: Mass Spectra of Complexes

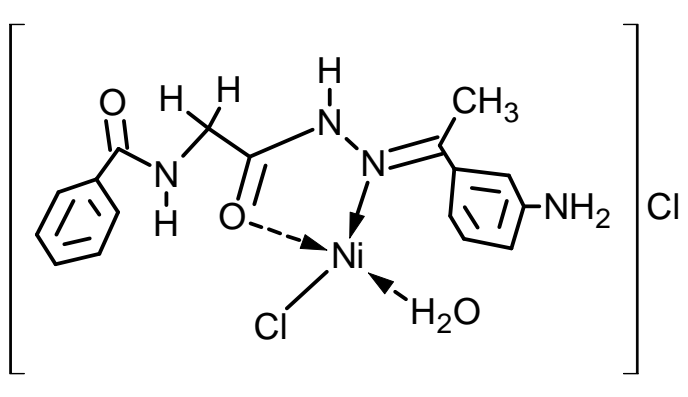<smiles>CC1=NN2OC([CH]NC(=O)c3ccccc3)=NC(O)(O1)[C]2N</smiles>

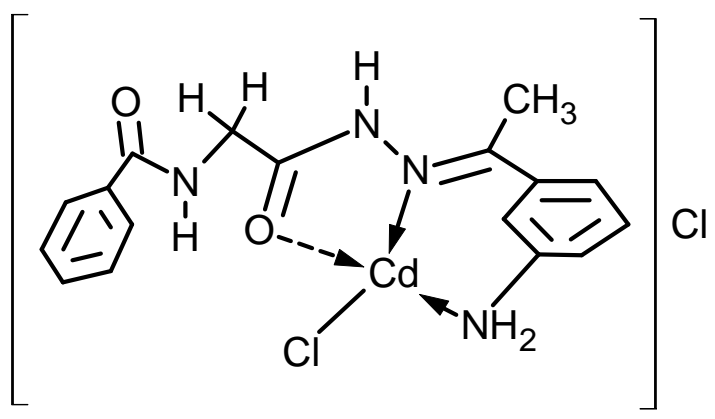

Fig. 4: Proposed structures of the complexes 
tetrahedral $\mathrm{Ni}(\mathrm{II})$ complex $^{31,32}$. Complex 2 is diamagnetic, ESR inactive and exhibits no characteristic absorbance in the visible region and these observations indicate that the metal is present in the cuprous form.

\section{IR Spectral Analysis}

The IR frequencies of the selected groups of $\mathrm{LH}$ and its complexes are presented in Table 2. A broad band at $3250-3300 \mathrm{~cm}^{-1}$ in the IR spectra of 1 and 2 indicate the presence of coordinated water in these complexes. The three amide bands at 1633 , 1552 and $1313 \mathrm{~cm}^{-1}$ observed in the IR spectrum of LH due to the benzamidic carbonyl group do not undergo any significant shift in the spectra of the complexes showing non-coordination of the above group in bonding. Coordination of the hydrazidic carbonyl group to the metal ion has been inferred ${ }^{33}$ from the observed hypsochromic shift in the amide I (7-16 $\left.\mathrm{cm}^{-1}\right)$ and amide II $\left(29-40 \mathrm{~cm}^{-1}\right)$ bands. Negative shift $\left(8-51 \mathrm{~cm}^{-1}\right)$ in the $\mathrm{n}(\mathrm{CN})$ and positive shift $\left(21-46 \mathrm{~cm}^{-1}\right)$ in the $\mathrm{n}(\mathrm{NN})$ stretching frequencies indicate participation of the azomethine nitrogen ${ }^{34}$ in complexation. Shift of the amide I band and the appearance of a new medium intensity band at $1519 \mathrm{~cm}^{-1}$ in the spectrum of 2 suggest -C$\mathrm{O}-\mathrm{M}$ bonding. This also indicates enolization of the hydrazidic carbonyl through tautomerism and subsequent bonding of the imidol oxygen to the metal ion ${ }^{35}$ in its deprotonated form as reported in the aqueous medium ${ }^{24}$. However, enolization does not occur in 1 and 3. The bands at 1026 and 597 $\mathrm{cm}^{-1}$ in the spectrum of the ligand due to wagging and rocking $\mathrm{NH}_{2}$ show negative shift in the spectra of $\mathbf{2}$ and $\mathbf{3}$ showing its involvement in bonding. The new bands with medium to weak intensity in the ranges 401 - 486 and 513-543 $\mathrm{cm}^{-1}$ may be, respectively, attributed ${ }^{36}$ to the $n(M N)$ and $n(M O)$ modes showing that the carbonyl oxygen and azomethine nitrogen have formed coordinate bonds with the metal ions while $A$ the bands at 362 and $410 \mathrm{~cm}^{-1}$ in the spectra of 1 and 3 are assigned to $\mathrm{n}(\mathrm{MCl})$ mode.

\section{${ }^{1} \mathrm{H}$ NMR Spectral Studies of Complex 3}

The ${ }^{1} \mathrm{H}$ NMR spectral data of the ligand and complex 3 along with the assignments are given in Table 3 . The existence of more than one isomeric form of $\mathrm{LH}$ at room temperature is shown by the splitting of peaks in the ${ }^{1} \mathrm{H}$ NMR spectrum of the ligand and the bands are assigned as reported ${ }^{24}$. The observed downfield shift $(\mathrm{d}, 0.18)$ and upfield shift $(\mathrm{d}, 0.11)$ of $-\mathrm{N}-\mathrm{N} \underline{\mathrm{HCO}}$ signals in the ${ }^{1} \mathrm{H}$ NMR spectrum of the complex indicates participation of hydrazide >CO group in bonding. Coordination through the azomethine nitrogen ${ }^{37}$ in the above complex is further supported by the upfield shift (d, $0.11)$ of $-\mathrm{NCH}$ and $(\mathrm{d}, 0.11)$ of $-\mathrm{NC}-\mathrm{CH}_{3}$ signals. Upfield shift ( $\mathrm{d}, 0.30)$ of $\mathrm{NH}_{2}$ signal in the spectrum of the complex also indicates participation of this group in complexation.

\section{SEM Images}

Scanning electron micrography (SEM) is used to evaluate morphology and particle size of the Schiff base metal complex. The SEM micrographs of complexes 1 and 3 and EDAX images are shown in Fig. 2. An ice square-like shape is observed in $\mathbf{1}$ while the images of $\mathbf{3}$ are spongy.

\section{Mass Spectral Analysis}

The FAB-mass spectra of complexes 2 and $\mathbf{3}$ are given in Fig. 3. The mass spectrum of $\mathbf{2}$ shows the molecular ion peak at $\mathrm{m} / \mathrm{z} 391$ corresponding to composition $\left[\mathrm{Cu}(\mathrm{L})\left(\mathrm{H}_{2} \mathrm{O}\right)\right]$. The mass spectrum of $\mathbf{3}$ does not show the molecular ion peak at $\mathrm{m} / \mathrm{z} 494$ corresponding to the composition $[\mathrm{Cd}(\mathrm{LH}) \mathrm{Cl}] \mathrm{Cl}$ suggested based on elemental and thermal analysis data. However, the peak at $\mathrm{m} / \mathrm{z} 459$ corresponds to the species $[\mathrm{Cd}(\mathrm{LH}) \mathrm{Cl}]$ that might have been resulted from losing the ionic $\mathrm{Cl}^{-}$ion outside the coordination sphere.

\section{CONCLUSION}

All the complexes formed are of the 1:1 metal - ligand stoichiometry. However, the ligand exhibits different ligational behavior. It acts as a uninegative species in copper complex 2 where enolization occurs at the hydrazidic moiety while it coordinates to the $\mathrm{Ni}^{2+}$ and $\mathrm{Cd}^{2+}$ ions as a neutral species. In complexes $\mathbf{2}$ and $\mathbf{3}$, the ligand acts as a tridentate species through the hydrazidic carbonyl oxygen, amine nitrogen and azomethine nitrogen and as a bidentate ligand in complex 3 bonding through carbonyl oxygen and azomethine nitrogen. All the complexes are tetracoordinated as shown in Fig. 4. 


\section{REFERENCES}

1. Yam, V.W. W.; Lo, K. K. W. Coord. Chem. Rev. 1999, 184, 158-

2. Hughes M. N., The Inorganic Chemistry of Biological Processes, $2^{\text {nd }}$ ed; John Wiley \& Sons, New York, (1981)

3. Angelique, Y. L.; Thomas, J. M. Chem. Rev. 1999, 99(9), 2711-2734

4. Richardson, D. R.; Bernhardt, P. V. J.B.I.C 1999, 4, 266-273

5. Zheng-Yin, Y.; Ru-Dong, Y.; Fa-Shen, L.; KaiBei, Y. Polyhedron 2000, 19, 2599-2604

6. Buss, J. L.; Neuzil, J.; Ponka, P. Archives of Biochemistry and Biophysics 2004, 421, 1-9

7. Sommer, L.; Maung-Gyee, W. P.; Ryan, D. E. Ser. Fac. Sci. Natur. Univ. Purkynianae 1972 , 2(6), 115-128

8. Shargi, H.; Nasser, M. A. Bull. Chem. Soc. (Jpn.), 2003, 76, 137-142

9. Sone, K.; Fukuda, Y. Inorganic Thermochromism, Inorganic Chemistry Concept, Vol. 10, Springer, Heidelberg, 1987

10. Ainscough, E. W.; Brodie, A. M.; Dobbs, A. J.; Ranford, J. D.; Waters, J. M. Inorg. Chim. Acta. 1998, 267, 27-38

11. Lu, Z. L.; Xiao, W.; Yu, K. B.; Deng, L. R.; Kang, S.; Su, C. Y.; Liu. J. J. Mol. Struct. 2000, 553, 91-99

12. Hursthouse, M. B.; Jayaweera, S. A. A.; Smith, A. J. Chem. Soc. Dalton Trans. 1979, 279-

13. Liang, Y. L.; Liu, C. M.; Ma, Y. X.; Li, Q. S. Transition Met. Chem. 1998, 23, 97-99

14. Haran, R.; Gairin, J.; Commenges, G. Inorg. Chim. Acta. 1980, 46, 63-67

15. Eyer, P.; Hell, W. Arch. Pharm. (Weinheim) 1986, 319, 558-566

16. Zishen, W.; Zigi, G.; Zhenhuan, Y. Synth. React. Inorg. Met.-Org. Chem. 1990, 20, 335-344

17. Rudolph, T.; Phillips, J. P. Anal. Chim. Acta. 1996, 34, 235-237

18. Parashar, R. K.; Sharma, R. C.; Anilkumar; Mohon, G. Inorg. Chim. Acta. 1998, 151, 201208
19. Gallego, M.; Garcia- Vargas, M.; Valcaral, M. Analyst, 1979, 104, 613-619

20. Lonibala, R. K.; Rao, T. R. Proc. Indian Acad. Sci. (Chem. Sci.), 1999, 111(5), 615-625

21. Lonibala, R. K.; Devi, N. I.; Devi, R. K. B.; Rao, T. R. Synth. React. Inorg. Met.- Org. Chem. 2001, 31(1), 179-194

22. Lonibala, R. K.; Rao, T. R.; Babita Devi, R. K. J. Chem. Sci. 2006, 118(4), 327-334

23. Sharmeli, Y.; Lonibala, R. k. J. Chem. Eng. Data 2009, 54(1), 28-34

24. Promila Devi, Th.; Lonibala, R. K. J. Chem. Eng. Data 2010, 55, 1166-1172

25. Promila Devi, Th.; Lonibala, R. K. Asian J. Chem. 2010, 22(7), 5369-5379

26. Sharmeli, Y.; Lonibala, R. K. Asian J. Chem. 2010, 22(10), 7541-7550

27. Yuimi, V.; Lonibala, R.K. J. Chem. Eng. Data 2011, 56, 3552-3560

28. Sharmeli, Y.; Lonibala, R. K. J. Rare Earths 2012, 30, 367-373

29. Vogel, A. I., A Textbook of Quantitative Inorganic Analysis, $3^{\text {rd }}$ ed.; Longman, England, (1961)

30. Geary, W. J. Coord. Chem. Rev1971, 7, 81122

31. Lever, A. B. P., Inorganic electronic spectroscopy, Elsevier, Amsterdam, (1984)

32. Henke, W.; Kremer, S. Inorg. Chim. Acta. 1982, 65, L115-L117

33. El-Gayel, E.; Iskander, M. F. J. Inorg. Nucl. Chem. 1971, 33, 107-

34. Braibanti, A,; Dallavale, F.; Pellinghelli, M. A.; Laporati, E. Inorg. Chem. 1968, 7, 14301433

35. Rao, C. N. R., Chemical Applications of Infrared Spectroscopy, Academic

Press, New York, (1963)

36. Inomata, T.; Moriwaki, T. Bull. Chem. Soc. Jpn. 1973, 46, 1148

37. Patil, S. A.; Kulkarni, V. H. Inorg. Chim. Acta. 1984, 95, 195 